\title{
The Datafication of Learning: Data Technologies as Reflection Issue in the System of Education
}

\author{
Ernst D. Thoutenhoofd ${ }^{1}$ (D)
}

Published online: 14 October 2017

(C) The Author(s) 2017. This article is an open access publication

\begin{abstract}
Like other parts of the social system, education is becoming an informationdriven venture: data technologies pervade all levels of the system. This datafication of education seems to take place alongside a general turn to learning that Gert Biesta has called learnification: a progressively singular focus on the manipulable features of individual learning in education. Given rapidly rising levels of datafication, it seems timely to take up Luhmann and Schorr's contention that education entails a technology deficit and discuss datafication as reflection issue in the system of education. Against their argument that human learning is not amenable to a technology, I develop the counter-argument that data technologies are replacing human learning outright with data at the level of organisation. Data thus present a concretely digital form of what Raf Vanderstraeten has called education as an ersatz order. In a data-driven form of organising education, human dimensions of learning become secondary to a systemic dimension: making learning visible as data and so susceptible to databased manipulation. The text treats school-wide positive behaviour support interventions as an evidence-based exemplar of this trend towards datafication in the system of education.
\end{abstract}

Keywords Education system · Technology deficit - Data technologies · Learnification · Datafication · Positive behaviour support

Anytime we talk about changing students' "behaviors", we run the risk of ignoring the students who are doing the behaving. We lose the human beings behind the actions. (Alfie Kohn 2011: 125-126)

Ernst D. Thoutenhoofd

ernst.thoutenhoofd@gu.se

1 Faculty of Education, The University of Gothenburg, Box 300, 40530 Göteborg, Sweden 


\section{Introduction: On the Datafication of Education}

Wiebe Bijker, known for his analyses of technology and society, is credited with a deceptively simple claim: 'We live in a technological culture-in a culture that is thoroughly influenced by modern society and by technology' (Bijker 2001: 19). Today this claim can also be expressed in a more particular form: modern culture is quite unthinkable without digital technologies and data. Today's data technologies, along with the common IT-driven dispositions and habits that have pervaded our everyday routines-where the hallmark of a professional workspace is a virtual desktop-are found to be game-changers in all the social practices invaded by them, from sports to business (Beer 2015; Kallinikos et al. 2015). An insatiable craving for data, not in the least corresponding to growth in evidence-based practices, is presently also boosting the digitisation of education systems world-wide. Besides a growth in didactic technologies and online educational environments, elaborate national and international educational data infrastructures are also being established, among other reasons in bids to better or more effectively govern education (Ozga 2009, 2016). With today's education systems becoming more and more data-driven, a growing primacy of data is becoming part of how educational concepts are understood. Large scale data collections such as PISA have been noted to disintegrate the place called school, with the link between individual pupil, local school and national outcomes becoming dissolved and black boxed into statistical forms that are often less than clear about how interrelationships are to be conceived: no theory of schooling - no reflectionremains (Hopmann 2008). This presumably means that any general description of education today needs to account for the exponential growth in data streams and what all these data are taken to 'tell us', or risk missing the very object under consideration altogether. A striking many concepts in common use in education are underway to becoming shaped by data. Put in more general terms, an increasing number of the categories and kinds through which we order and make sense of the world are an artifice of data technologies. School league tables are a clear case in point, as are bibliometrics as proxy measures of research quality in higher education, but there are increasingly many others; soon they may be too numerous to be conscious of them. This observation is what I will sum up, into a single notion, as the 'datafication' of the system of education. It is, to wit, not simply that there are ever more data in the world; it is sooner that ever more often, what is presented as real or factual is a product of data, with traceable lines of correspondence back to an originating rich and messy reality running the risk of being altogether lost. My core proposition will indeed be that this also applies to the idea and practice of learning under conditions of extensive data collection on learning and databased analysis of learning. In a supposed information age, both the idea and the practice of learning risk becoming data products.

\section{On the System of Education in Technological Form: An Overview of the Text}

So, technologies are spreading through education and are changing education. It thus seems useful to begin the descriptive work of clarifying towards what particular technological form the system of education appears to be changing under technological conditions. We should expect such clarification to point towards noteworthy consequences of that form. To help this process of clarification along, I will make use of a case study: school-wide positive behaviour support or school-wide PBS, which I take to be a 
successful education technology. The main reason for my selection is that school-wide PBS presents a clear example of the datafication of learning, without presenting as a technology, as such. Therefore I will start what follows with an introduction to that particular case. I will then set out in some more detail how a re-specification of education is underway via learnification and datafication. I will suggest that both processes reflect the same data-based trend. That trend seems to be the absorption of human(e) qualities of educational action by technological expedience in a particular form: the innate numbersbased 'logic' inherent in the production and circulation of data, using algorithms of computing and science. In my case study, this databased absorption recaptures education as a narrow set of technical features of visible learning behaviour that can productively be turned into the data needed for evidence-based decisioning. The product of that technological absorption of pedagogical relationships and action is still called education, but it is now more visibly and so manageably recast as an ersatz order (Vanderstraeten 2002: 249). In that ersatz order, the system of education has found a digital escape from the incalculabilities and statistical liabilities of human qualities and values, and orients itself to a form of rational decisioning that is itself a social science technology and product. As ersatz order, the system of education attains a digital and an organisational form able to respecify learning along whatever lines are needed for optimal data collection and analysis, for which it uses evidence-based technologies. ${ }^{1}$ I will conclude my redescription of education systems under information technological conditions by noting that the substitution of learning by data shifts the focus of educational critique beyond questioning the possibility of education technologies (Luhmann and Schorr 2000) or the possibility of education as such (Vanderstraeten and Biesta 2001), to questioning the possibility of being and becoming human under present education systems.

\section{On School-Wide Positive Behaviour Support as Technology}

School-wide PBS practices are spreading across the United States (Bradshaw et al. 2008) as well as in other advanced western education systems (Grey et al. 2016), including more substantively Norway and now also in Sweden (Sørlie et al. 2015). By 'advanced' I mean in this case education systems in which detailed data collection from schools has become nationwide organisational routine, along with detailed and fine-grained systems for auditing, guiding and monitoring the quality and effect of central and local governance of education being in place. It has in that context been noted that education is becoming ever more data-driven and data-networked (Lawn 2011), including also the embedding of organised educational science (Lawn et al. 2010) and evidence-based working, in these systems of education. School-wide PBS schemes all fit this description, since their evidence-based practice orientation ensures that extensive forms of routine data collection are explicitly named and often stressed in school-wide PBS studies published to date (e.g. Sugai et al. 2000; Luiselli et al. 2005; Sugai and Horner 2006; Warren et al. 2006; Bradshaw et al. 2008; Brandt et al. 2014; Madigan et al. 2016; Sørlie et al. 2016).

School-wide PBS is the planned, systematic and ongoing monitoring and (positively) controlling of pupil behaviour by school staff — who may in turn be advised by scientific or trained experts-using psychological and social science reporting protocols (see Kincaid et al. 2016 for a discussion on definitions). The suggestion that pupil behaviour is under a

1 In MOOCs or 'massive open oline courses', for example, learning becomes conceived as patterns of mouse-clicks in temporal units of analysis, see Van Dijck and Poell (2015). 
controlling form or regime in school-wide PBS schemes is warranted by repeated insistence in the literature that schools loyal to the scheme establish strict intervention routines. Where indications give rise to pupils being deemed at risk of their learning being adversely affected by behavioural characteristics, corrective behaviour modification techniques are systematically deployed by school staff in response, with their effects in turn being monitored and evaluated. To this end, pupils are most typically ranked on school entry, or at the start of the school's participation in a school-wide PBS scheme (Walker et al. 1996), on a categorical scale aimed at 'primary', 'secondary' or 'tertiary' prevention of behaviour deemed an impediment to learning. Lest we forget, in this ordering sense too, school-wide PBS already is a technology. Like all other educational tests and assessments, it establishes both a technique and the instruments needed for ranking and monitoring that involves pupils and staff in a school, as well schools committing as organisational entities to the enforcement, administration and reporting of PBS prevention and intervention strategies. These intervention regimes are technologies, second, in the sense of typically involving scientific knowledge encoded as practical instructions, for example deriving from functional behaviour assessments and behaviour management systems based on the possibilities of new motive acquisition (McClelland 1965) and using contemporary forms of operant conditioning derived from behavioural psychology. Schools may be monitored for intervention loyalty (Gage et al. 2015) by regional or national centres of expertise on schoolwide PBS. Altogether, and as part of the third, data-driven sense of being a technology, substantive amounts of pupil behaviour and school loyalty data collect in education with the spread of school-wide PBS practices.

There is, in itself, nothing much new to either what school-wide PBS seeks to achieve in pedagogical terms, nor to the behaviourist means that it uses even under social constructivist credentials (Robinson et al. 2008). On a surface level, what school-wide PBS pursues is what many schools, parents and teachers wish for and that behavioural scientists in particular have searched for as methodical guarantee for decades: well-behaved pupils that pursue their education with due diligence. In that pursuit, school-wide PBS schemes apply to school pupils what at fundament remains a form of operant conditioning, steering their behaviour via a variation of the praise/punishment schema - the consistent and persistent encouraging of sought behaviour and the discouraging of unwelcome behaviour by teachers and other school staff-in order to instil in all school pupils a positive focus on learning that is presented as being in everyone's best interest. Hence school-wide PBS is unique not in respect to what it asks of pupils and teachers, but in much more vigorously pursuing that behaviour as a general classroom state. This vigour translates into data via accountability and the need for evidence. The product sought is behaviour that is visibly focused on learning and the absence of behaviour that visibly detracts (other pupils) from learning. Otherwise put, school-wide PBS is positive in the precise sense of seeking a common, exception-less will to learn expressed as visible behaviour, or as behaviour that can both be counted and accounted for. By getting pupils to show a primarily positive disposition towards learning while in the classroom, school-wide PBS seeks to optimise instructional time and can thereby claim to assist schools in achieving their goals and targets. To be clear on this point: my account here aims not at passing judgment on particular credentials it seeks for itself, but at highlighting the technological and data driven character of the learning that school-wide PBS interventions seek. My description should enable a focus on what learning comes to mean, in such a highly technologised context (Biesta 2015a, b). 


\section{On Evidence-Based Education as Technology}

Aside from pursuing an exception-less will to learn, what is also still exceptional for many schools in applying school-wide PBS schemes is their strict insistence on evidence-based methods. Whatever else may be claimed for a definition of evidence-based methods, PBS is both a technology and a product of science. In that science technology, scientific evidence (needed for generating suitably guiding predictions about the intervention's effectiveness) equals the collection and processing of data in substantive quantity and preferably in enumerable form, bringing along with it a self-evident focus on the statistical handling of data. The persistent collection and use of scientific evidence also equals the routine collection of data from practice. This in turn also foregrounds a particular (namely: professional) sort of data being produced, since we do need to recognise that data collection never falls to pupils or their parents-it falls to professionals and institutions, entities which can be tasked and entrusted with such routines. The persistent requirement of scientific evidence on any significant scale - that is, for entire school populations and more into districts or councils and upwards into regional and national systems-furthermore equals the collection of data on a substantive or 'big' scale, which brings infrastructure along with it. And all this combines with the scientific need for rigour, that is, for generally high standards of dedicated effort, for persistence, for readiness to fit social phenomena to a limited number of data categories, and for engaging in repetitive data checking, followup and evaluation routines; which in turn brings with it the need for both expertise and training.

Bringing together a robust data-collection or evidence-base is therefore non-trivial, to say the least. Not only because the widespread availability of powerful, infrastructured computing resources and readiness to make data categories 'work' and upkeep strict standards of working, are necessary for operating school-wide PBS on a significant scale; but even more because this work risks becoming supervenient on the main task of educating pupils (Lewis and Hardy 2016; Lingard and Sellar 2013; Hardy 2015a, b; Hardy and Lewis 2016). The main task of teachers is to educate, to provide pupils with an education. Hence it should not prove surprising that even in advanced western systems of education, the levels of instrumental pragmatism and material resourcing that are needed in order to meet the sorts of scientific standards of rigour encapsulated in such schemes as school-wide PBS, remain a real challenge to implement in practice. This is something that PBS researchers have themselves of course also discovered (Reinke et al. 2013; Grey et al. 2016). In summary: evidence-based working reflects not only a scientific obsession with the collection of enumerable facts, it is furthermore an essentially technological intervention in what is regarded as knowable and worth knowing that alters what learning and education are and what they involve, from a particular institutional perspective. Indeed, one à priori claim of this text is that data technologies as such re-specify learning and education, for all involved, on terms commensurate with computational means.

\section{On Bildung and the Ability to Learn as Contingency Formulas}

Learning has been theorised by Luhmann and Schorr (2000) as the form through which the system of education seeks both specialisation of the core it pursues and seeks optimal connection with other part of the social system by delivering useful assets. Its core useful asset is selection (the ranking and ordering that are achieved through qualifications and test 
scores). Under Luhmann's general social systems theory (Luhmann 1995), the contemporary social system is distinguished by its functional differentiation into various subsystems (Luhmann 2012, 2013), of which education is but one (Luhmann and Schorr 2000: 29). Luhmann's main claims are attendant to treating the social system as an example of autopoiesis; that is, as a system that is (self-)referentially closed in the precise sense of continuously generating the resources needed for bringing itself and its various subsystems into presence. Differentiation is thus part and parcel of autopoiesis, or put more precisely: it is the outcome of structural constraints within the overall social system giving rise to independent processes. In education, the process of instruction is the outcome of structural constraints on learning and competent practice following the social and economic reorganisation of the social system under industrialisation conditions (Luhmann and Schorr 2000). Instruction, including how and to whom it is applied, has become ever more organised and specialised, including the emergence of state schools, national populations of pupils and curricula, assessments and qualifications, a teaching profession, and organisation in a particular form.

Differentiation of the system of education brings the school into being as a distinctive interaction system. According to Luhmann and Schorr, the school provides for an interaction system that concentrates people of the same age, for the purpose of triggering and pursuing a professionally steered type of cognitive development: its function is to provide people with an education that armed them for life in society (Luhmann and Schorr 2000: 33). The school is different from the family, among other things because it makes pupils aware of being essentially alike other pupils in developmental attributes, which in turn highlights ongoing possibilities of selection in a particular form, namely via one's performance on developmental tasks. In schools, pupils become self-aware of being both directly and continually comparable to others in 'rational' - that is, in apparently objective, precise and systemic - respects (Dreeben 1968). In Luhmann and Schorr's account of education systems, this constructed form of rationality assumes equality of opportunity as common and fair starting principle. Thus the system of education could, in that particular sense reasonably, take on the task of initial social selection of people for life courses within the social system, through such means as monitoring, assessing and testing, school transitions, and a system of qualifications.

Under the general Humboldtian notion of Bildung, education assembled a community of learning individuals who are taken to pursue what is both of general and particular interest to them. According to Luhmann and Schorr, the notion of Bildung also inspires the assumption that the same logic, namely the free pursuit of particular aptitude and interest, forcibly applies to all others. Hence education becomes 'the realization of the general in the particular, namely, turning the way in which the individual acts towards himself into a relationship to the world' (Luhmann and Schorr 2000: 156). One notable consequence that this particular social edifice entails is that school discipline problems too become understood as problems of 'individual dealings with single pupils' (Luhmann and Schorr 2000: 156), which further stresses the selection function of education - and it should be added, provides a key growth condition for assigning pupils to at risk categories. Within the terms of reference of Luhmann's general social theory, the idea of Bildung thus captures a symbolic structure that is needed to integrate the functional operations of subsystems - in particular, the operation of social selection-with the general social system's ongoing differentiation, or unfolding into increasingly specialised subsystems. Such symbolic structures are called contingency formulas within the system theory. Contingency formulas control the relationship between function, performance and reflection (Luhmann and Schorr 2000: 67) and at a more abstract level they provide a generally unifying conception 
of the direction in which the subsystem is specialising. They are contingent in the precise sense of remaining continually re-specifiable. They tie the generalities of social systems to the specificities of everyday life under development, acting teleologically as the indication of a direction and as the intensification of some collective or public ideal. Bildung, for example, became plausible with the Enlightenment idea that the future was open to the effects of progress and so open to improvement and the elimination of things existing in the present, such as ignorance or lack of skill. In Luhmann and Schorr's theory of education, contingency formulas therefore play a key role also in education's selective procedures. They foreground organised or planned learning as a more or less successful and meaningful activity, and presuppose that learning is toward some more or less attainable goal, irrespective of whether that learning is considered opportunity, responsibility, obligation or duty.

The process of determining learning that is successful becomes thereby increasingly modelled on cognition, not in the least under the influence of scientific research. According to Luhmann and Schorr, the idea of all-around education of Bildung has been gradually replaced by this new scientific focus, with the contingency formula of the ability to learn. The ability to learn replaces a focus on developing one's orientation to the world with a focus on learning itself, as general application. This contingency formula better fits a functionally differentiated social order moving towards ever greater complexity and interaction speed, which necessitates ever greater individual ability to adjust continually to further demands made by the social system. Luhmann and Schorr note that the education process ends up making itself permanent (Luhmann and Schorr 2000: 95). The ability to learn is therefore conceived in Luhmann's theory as a special competence that is to be applied intensively, and so must be available permanently. To have the ability to learn is to be always ready and willing to learn. It entails the constant anticipation of learning in order to be successful. An important system-evolutionary characteristic of the ability to learn is therefore that the formula 'symbolizes self-reference and thus being closed' (Luhmann and Schorr 2000: 96). It is no longer possible to escape education, since what is considered useful (to know) is henceforth exclusively a learnt ability to learn what is useful (to know), which no longer excludes anything. A further clear consequence of the shift from Bildung to the ability to learn is that it presupposes further technicisation, a focus that is centred on the —scientific_optimisation of learning as process (Luhmann and Schorr 2000: 98).

\section{On Learnification}

For Biesta (2002) too, the movement from Bildung to the ability to learn analysed in Luhmann and Schorr is part of late modernity. Biesta's conception is however notably different in some key respects, since it focuses more on a description of living under postmodern conditions. Key to the postmodern condition in Biesta's account is a form of general scepsis arising from the realisation that not all progress to date has shown to be desirable and unproblematic. Hence, Biesta suggests, the idea of becoming modern now carries with it a marked ambivalence towards possibilities that also challenge what it means to be educated or cultivated. It is, so to speak, no longer quite so clear what exactly is invoked by the Kantian thought-figure of rational autonomy, since the general or universally rational-what it is right and good to do by way of logical evaluation of clear premises - turns out to rich in unintended consequences and subject to plural conceptions. The idea of a general good is thus increasingly challenged in the confrontation with a 
plural world in which all that is rational and all that is not confronts differences (Biesta 2002: 343). Biesta thus foregrounds the need for a renewed settling of the question what education is for, proposing in response a tripartite of qualification, socialisation and not in the least, subjectification. Since each of these dimensions call for attention in a different form, their synthesis is difficult (Biesta 2009).

Cast parallel to Luhmann's theory, Biesta's description of the postmodern condition suggests that the functional differentiation that is underway, of the social system into increasingly differentiated subsystems, occurs alongside pluralisation with respect to grasping, or coming to terms with, that ongoing functional differentiation. Luhmann too has noted that, in respect to reflexivity within subsystems, not one singular or universal rational view or purpose is discernible (Luhmann 1998). In educational perspectives, a general confidence in mastering the world via certainties-knowing as discovery of facts and confidently acting upon those in a universalising manner that is characteristic also of centralised education systems - is thus giving way, according to Biesta, to responding to what and whom is other, and in particular undesirably so. Such 'detrimental otherness', inter alia, includes a sharp rise in the number of pupils who present a challenge to effective education (Tomlinson 2012). This reasoning might thus be able to account for present proliferation in school-wide PBS practices.

Given a plural world of differences, making education certain means finding ways to deal with doubt, which involves negotiating, ordering and evaluating forms of learning, as well as developing the ability to collect and interrogate facts. Along with theories of learning that foreground the constructed nature of knowledge and the commodification of learning as a marketable good however, an increasingly value-oriented relationship that is emerging between the state and its citizenry is also helping to replace general rational autonomy with the multiple variable dependencies of personal interest (Biesta 2004). The personal interest is in education as human capital, a resource able to give individuals competing for scarce resources and privileges a social selection advantage. In this neoliberal conception too, the idea of learnification captures a trend towards ignoring the universal question what constitutes a good education, in favour of a more purely technical facilitation of learning as process in itself (Biesta 2009: 36-37; Pirrie and Lowden 2004: 521). As with the ability to learn as contingency formula, the combined effect of politics harnessing 'knowledge' economies and the neoliberal idea of learning as private enterprise compels the belief that there can be no escape from learning. Lost in learnification from this perspective too are previous libertarian ideals (the freedom to learn and learning as emancipation), a conclusion that Biesta (2015a, b: 236) notes lends a particular significance to the notion of 'lifelong learning' as a kind of conviction to it. Learning is not liberating. Instead, one is compulsively and competitively bound to it for life, as well as subject to its selection function. It should finally be noted that this observation equally applies to policy aimed at an 'inclusive' education 'for all': no-one escapes the system of education's selection function.

In summary of the sections so far, learning has become a constrained, highly defined cognitive and social performance that one must be ready to engage and embrace also as continuous selection throughout life, as an attitude learnt in and as education. Driving and managing selection through learning, the system of education is technologising and increasingly turned to pupil and school data. Education is thus advancing towards a more technological and data driven form of what in Luhmann's social systems theory would be called organisation. Its proper description however amounts to something of a challenge vis à vis Luhmann's own writings, since it directly contradicts his repeated conclusion that the system of education, by the very nature of education pursuing the cognitive development of 
individuals, does not allow for a technology to play a major role; a situation he describes as the technology deficit in the system of education. I propose to start my resolution of this deficit assumption in a discussion of organisation.

\section{On Organisation}

Organisation is, put simply, the process by which a few selections reliably determine many selections (Luhmann and Schorr 2000: 139). As do all evidence-based approaches, selectivity being a key principle of their possibility, PBS readily aligns with organisation under that definition. In PBS schemes of working, a few key selections are in focus: pupils are ordered by both background — which is used to forecast their risk of not learning — and their readiness to learn, as determined by their school behaviour. These two selections are then didactically operationalised via a pedagogically understood and so enforceable schema of operant conditioning, into a locally determined set of guiding instructions to education staff, in order to foster school-wide effects in the direction of learning that is free from resistance and so uses teachers' instructional time optimally (Madigan et al. 2016). The point in describing the PBS intervention schema in this way is to highlight that such evidence-based schemas are possible only as technologies; that is, they can function only by way of standard, well-executed and so reliable teaching routines alongside consistent and persistent data collection, the need for both of which is therefore repeatedly stressed in most writings on PBS. I referred to this trend of technologising educational governance as the datafication of education: it is becoming based on routine teaching and data collection techniques, operating in a dependable and iterative fashion. Organisation thus becomes ever more substantively entrusted to standardised data generation and processing techniques. Data produced in and collected from such routine social practice are then used in calculating key determinants of that practice, using a minimum number of theoretically asserted principles (e.g., learning behaviour leads to learning) that are thereafter dogmatically applied to practice. Science here forces data production into an enumerable form, artificially generating a better predictability of pedagogical outcomes: practice is altered to cohere around assumptions that the data chains can sustain. The above amounts to a more technological redescription of evidence-based working more generally, a redescription that furthermore seems wholly consistent with Luhmann's idea of organisation.

It will be helpful at this point to try and draw a clear line between what can be technologised in this way (the features of the educational enterprise) and what cannot: individual beliefs and motivations, pedagogical relationships, and caring. This line coincides with a form of incommensurability - between systems, in systems theory-that is called the problem of multiplicity. Multiplicity marks a sharp distinction that Luhmann notes needs to be made between individuals and society that also runs through his social theory, and that gives rise to what Luhmann considers as the technology deficit (the improbability that technologies can act 'educationally') in the system of education. Once it is clear what is entailed by the problem of multiplicity, it will be easier to see how and why technologies such as school-wide PBS operate at the levels of behaviour and data, sooner than at the levels of learning and education. My treatment of the multiplicity problem below is substantially indebted to texts by Raf Vanderstraeten. 


\section{On Multiplicity and Bifurcation}

One clear consequence of Luhmann's theory of social systems is that its distinction between human beings and social systems is upheld by social systems and psychic systems (individuals) being taken to present two separate and closed systems. The two systems are thus considered entirely incommensurable and 'external to one another' (Vanderstraeten $2000 \mathrm{a}, \mathrm{b})$. Vanderstraeten points out that consciousness or the thoughts of individuals, and communication or the circulation of messages that forms as the social system, are altogether different modes of autopoietic reproduction in Luhmann's social systems theory: put precisely, they do not participate in each other's self-renewal. Only thoughts can give rise to further thoughts in individuals. Only messages can give rise to further messages in the social system. Thoughts can occasion messages and vice versa, but this involves efforts and outcomes that only stress their distinctive functions in the closed operations of both systems. For the discussion here, what seems most striking among the many consequences of Luhmann's discounting individuals' participation in social systems, is probably that the concept of socialisation is almost entirely absent from Luhmann's social theory. This is not, according to Vanderstraeten, because issues of socialisation have failed to attract Luhmann's attention, but because the idea of socialisation demands, on principle, an altogether improbable alignment in both the orientation and the functions of social and psychic systems. In short, the possibility of socialisation - and with it, the very possibility of education itself (Vanderstraeten and Biesta 2001) — becomes a question that needs to be settled. Vanderstraeten is most clear on this point:

...socialization can only be self-socialization. For human beings, participation in communication cannot result in the transmission of knowledge, nor in the internalization of the norms and value orientations of a social group. The meaning of norms, rules, habits, etc. which are 'transmitted' does not remain the same. In the different participating systems, these elements have different meanings. They signify different things, while they select among different possibilities and lead to different consequences. (Vanderstraeten 2000a: 589)

The unlikelihood of clearly predictable patterns of meaningful interaction between social and psychic systems being possible, Vanderstraeten continues, is given by the fact that attempts at socialisation (or: attempts at instruction) necessarily create bifurcations, a forced conscious choice that individuals must make, as psychic systems, between conforming or not-conforming to expectations that others communicate to them. This is much akin to the claim that while it is possible to learn, the direct transfer of knowledge via teaching is both highly improbable and ethically undesirable (Rogers 1969). Since every norm or rule-every new injunction on pupils to know or remember this-brings with it that dual orientation towards its acceptance or its rejection, injunctions or teachings can not be items for direct acquisition into a psychic system's establishment of itself, in itself, in Luhmann's theory. Instead, the statement of a norm or rule, expressed as expectation that it be fulfilled, is a message of and in the social system and it fulfils the functions only of the social system. It is at best a message that can only and must be evaluated, as such, by a recipient. Bifurcation thus marks the distinction between messages in social circulation within the system of education and what it offers as possibility to an individual psychic system. Bifurcation establishes this form of multiplicity - the private orientations, goals and functions of pupils, and teachers, and others, as inevitably distinct from the social orientations, goals and functions of learning, instruction and education-as fundamental to 
the system of education's engaging with individuals, since it introduces a potential for resistance that it itself generates by way of its educational demands: in short, the addressee of the messages of education and which intends the addressee's education has, to name but one possibility, 'the opportunity to reject the communication because it intends her education, if she refuses the role of someone who needs to be educated' (Vanderstraeten 2000a: 592).

\section{On the Idea of a Technology Deficit}

Needing to deal with multiplicity, but as social phenomenon, makes that education is conceived of as a communicative activity, one that intends to 'influence and improve the functioning of psychic systems' (Vanderstraeten 2000b: 8). The educator can however only educate by way of knowing about human beings, while pupils can only educate themselves via knowledge that may or may not be taken to be of a similar kind: here education presupposes the mutual self-alignment with the other (Luhmann and Schorr 2000: 176). The implication of this dependency on good-will, or the continuously unstable complicitness of learners in their education, is according to Luhmann and Schorr that education necessarily remains fundamentally an art, that is, resistant to a reliable technology of instruction. Put somewhat differently, education involves an ethical dimension that pivots on a notion of freedom of the will-that is, on persons choosing how to interpret rules, norms, expectations and requests-being the unassailable mark of conscious psychic systems, and this thwarts possibilities for turning instruction into mere technique. The dependency on psychic systems, which it can neither interiorise nor regulate, thus gives rise to a technology deficit characterising education, according to Luhmann and Schorr. Teaching cannot be made into a science, because learning falls outside the sphere of rational prediction. Indeed, learning takes place outside the circulation of messages of the social system.

My suggestion is that is precisely here good scope, also within Luhmann and Schorr's own theory, for educational technologies that exactly leave learning outside, or behind, as a relevant consideration altogether. As Vanderstraeten has put it (2000b: 22), if the system of education is to convincingly fulfil its public role of equitable initial selection, it needs recourse to a 'search for techniques that might accomplish what cannot be accomplished', and that operate on modest ambitions. Learnification is, in those terms, a technique that models a particular kind of behaviour that seems visibly focused on learning, and so makes it measurable. In reducing learning to a particular behaviour that is both visible and measurable, the system of education brings about its own unique normative code, 'namely the distinction between acceptable and unacceptable patterns of behaviour, approval and disapproval, right and wrong', and so on (Vanderstraeten 2004: 264). The internal distinctions that are thereby introduced, such as the praise/punish of school-wide PBS or the right/wrong and succeed/fail of assessments, are then both the form in which education selects and the template used for turning education into a technological regime. Now this seems, to be precise, a point of translation at which an instructional technique can absolutely meet with an educational technology as such, and so force the system of education towards new technological levels of functional organisation; it seems also to be the form in which school-wide PBS has become successful. 


\section{On Countering the Technology Deficit in Education}

My account thus seems to offer grounds for ignoring repeated scepsis by Luhmann and Schorr about taking the possibilities of educational technology to run education seriously. They suggest that in much educational scholarship that has investigated the role of science and technology in education, a close relationship between research technology and educational technology has been implied, as if in education they would be one and the same thing (Luhmann and Schorr 2000: 233). Yet this does set out the very development that is taking place in education and elsewhere via evidence-based technologies: the relationship seems an observation (an explanandum) and not an implication (an explanans). A crucial possibility that Luhmann and Schorr seem to have overlooked is what Biesta (2010: 491ff) attributes to Latour's (1987) concept of metrology: namely, to re-align the furniture of the world so that it is consistent with a science or technology. In the actor network theory of Latour, metrology implies an inversion of the standard conception of science as discovering facts that exist in the real world outside the laboratory. By contrast, metrology traces the various steps that are typically undertaken in order to bring what exists outside the laboratory in line with principles that have been established inside the laboratory for what exists outside it. In such cases, scientific work is less about discovering the world through science then it is about the simultaneous unfolding of science, technology and society as a single force. A case described by Latour is known as the 'pasteurisation of France', in which Latour (1988) recovers how the pasteurisation of milk as sensible response to the discovery of microbe-related disease entailed at least as much work and achievement outside the laboratory as inside it: hence Latour's claim that science is politics by other means. As part of his thoughts on a sociology of measurement, Steve Woolgar offered a telling description of the reconstruction of intelligence as quotient (IQ) and its effect on how intelligence is thinkable along similar lines:

Whatever it is that IQ tests measure, they assuredly do it very well. The results can be seen to be consistent, cross-correlated and so on. The problem begins when we suppose that these numbers measure something called intelligence. Or rather, when we suppose that they are measures of the thing we always thought was intelligence before IQ tests came along. (Woolgar 1991: 324)

It is along these lines of understanding science and technologies as social actors that Luhmann and Schorr seem to be making two questionable assumptions with regards to technologies. First, they assume that technologies must meet the condition of capturing form-critical attributes of learning. This supposes that learning is something fairly fixed out there in the real world: that learning is a natural kind. Yet, that there is no such learning as a natural kind seems given in Luhmann and Schorr's account of contingency formulas, for example. To put this differently: the supposition that learning is a natural kind seems inconsistent with a historical analysis that determines it to be a product of the education system's specialisation.

The second assumption they make is that the operations of the social system, while not involving persons as such, are still those of a social system sooner than of a technical system, also in the ongoing development of organisation. It reflects an apparently dim view of technologies as such, or at least a dim view of technologies co-shaping an interaction system (such as education) at all. In this respect Luhmann's theory of social systems still seems wedded to an entirely anthropocentric or perhaps sooner natural conception of social systems: social systems are taken to be naturally occurring rather than artificial or 
technological systems. While in both Latour's metrology and Woolgar's sociology of measurement theses on the other hand, the point is sooner that technologies tend to transform what it is that they are applied to, reducing the space for an essential 'nature' of things. Their analyses suggest the possibility that data technologies, or indeed facts generated by science, are capable of altering what is within the purview of relevance much along the lines of contingency formulas. The position chosen by Latour and Woolgar reflect their interest in technologies as material semiotic actors, a form of agency that is entirely overlooked in Luhmann and Schorr's account. On this view, technologies are independently involved in the production of the social system - that is, on functional and material terms that entail no particular foundational assumption about psychic systems. While it may therefore be correct that the language of scientific analysis cannot be used in instruction (Luhmann and Schorr 2000: 142, 233), it is conceded that what is entailed in instruction is from the level of organisation endlessly reconfigurable. That is all technologies need. It makes it possible for extensive data collection to substitute for learning, by making instruction and entire schools adhere to the principles selected for their operations by a theory that accounts for learning selectively; that is, in data form, in exactly the sort of backwards interpretation scheme that Luhmann and Schorr allow for in their reference to it as a Kantian figure of rational thought (Luhmann and Schorr 2000: 145, 183).

\section{On Education as Technology-Centred Ersatz Order}

The transformation of education into organisation is what Raf Vanderstraeten has called an ersatz order. It comes about because the inner world of pupils is not available to control, so that instead, the system orients to decisions made within the system itself. Under an ersatz order, 'it becomes important to be a "good" student' in the clearly visible terms of, for example, proficiency tests (Vanderstraeten 2002: 249). Using such systemically understood data on pupil behaviour as well as schools' intervention loyalty, school-wide PBS schemes can set about, with the earlier noted vigour that is given only to data technology, eradicating from practice those phenomena that are not in keeping with what the data, when in good working order, should be showing. Anomalies can thereby be attributed to weaknesses in the system of operations, for example to a lack of loyalty that school administrations are showing to the intervention schema or to the data collection routines. With its connotation with an inferior, fake or mock substitution of something real, what the ersatz concept also neatly captures is, as I have described it, the substitution of learning as complex human relations-based experience with behavioural science data. The data record learning as manifest behaviour, induced through a narrow selection about what should pass in classrooms if schools are to help avoid social problems.

At this level of making decisions, a problem of conceiving how technologies enact as a substitution what they measure also confronts Biesta's critical analysis of evidence-based approaches. The problem with those, as Biesta sees it, is in essence one of exclusion, in which the risk is that the factual information collected in evidence-based approaches becomes the only evidence considered in shaping educational practice. This is a principle of selection. Biesta quite rightly points out that in such cases an 'is/ought' distinction might instead be made that separates out the facts (what 'is') from the values that might be pursued (what 'ought' to happen). This returns us to the Enlightenment idea of progress from a dim past to a bright future: 'what is' does not exhaust what we wish for. In Biesta's conception, giving education direction necessarily involves human value-judgments that 
cannot be based on the facts of the (past) matter alone (Biesta 2009: 35). Yet the problem here is deciding on who or what gives education direction. A similar comment applies to the distinction Biesta makes between what I too earlier called the technical validity of evidence-based data collection and the normative validity that is needed to decide on the matter of what purpose is being pursued with effectiveness, as such. Effectiveness is seen as an instrumental value, that is still oriented towards some human goal or purpose-and scientific effort ought precisely to be directed at clarifying purpose, rather than being pressed into the blind service of effectiveness (Biesta 2009: 36). Research into educational effectiveness is blind when it ignores the question what education is effective for (Biesta $2015 \mathrm{a}, \mathrm{b})$ and so hides reflection issues present in the system. However, what both these problematisations presuppose is that what is treated as the object of shared concernnamely, that what we take education or learning to be-is something stable and 'out there', if perhaps something that is under debate and that needs continual clarification. This supposes that education cannot be reconstructed into a form that no longer carries a primary orientation towards human enlightenment or emancipation: a form that is, instead, a technology. The supposition remains anthropocentric in taking for granted that there is some kind of human 'we' who are in the driving seat of making reasonable choices for 'our' system of education. It also assumes that the system of education has cause to move from technology to culture.

\section{Conclusion: On Data Technology as Reflection Issue in the System of Education}

Before concluding my description of technologies in the system of education as reflection issue, a note is in order on the concept of technology itself. In line with Luhmann and Schorr's (2000: 131-132) claims, reference to technology has clearly been used here throughout in a social theoretical sense, namely as the sum effect of intentional engagements in which explicit rules are used to bring about the ordered work processes needed for moving towards some goal or objective. As Luhmann and Schorr note, technology 'seems to be the key to the question of whether, and in what forms, a system "becomes hierarchical" - which means, how the system is ordered into several levels and is reintegrated via cognition and decision processes' (Luhmann and Schorr 2000: 132). In that more systemic sense, abstracted from learning, it surely seems strange to have characterised education as entailing a technology deficit. Rationalising technologies by now drive most organisation, in the deliberate sense of computationally extending the number of operations that can be hierarchically controlled via reliable and well-practiced routines far beyond human comprehension. It is here that there surely is a most ready symbiosis with the instrumentalisation of predictive ends - the ability to learn, observable as learning behaviours-in evidence-based scientific methods. What technologies and predictive science conveniently share is a dual premise, namely that causal factors may first be isolated and then stabilised by turning them into robust measures. Both of those are technical preconditions for the possibility of sustained data collection that enables comparisons across time (Biesta 2015a, b). Technologies, in short, are turned to the production of cause-effect relations (Vanderstraeten 2004: 267). By implication, uncontrollable resistance to the goals of the system of education in such a technological form needs ideally to be ruled out for all actors: for pupils, but also for teachers and schools. This is because resistance, the product 
of multiplicity, is an essentially unpredictable factor that continually threatens to undermine the quality of data being collected.

In conclusion, Luhmann and Schorr, writing in 2000, can still doubt that education will succeed in addressing the technology deficit. However, the narrow selection that is achieved by present databased technologies, of both instructional and data collection routines, and of learning as only a kind of behaviour standing in an observable relationship to what can be monitored and documented - that is, turned into data-seems to be driving a rapid technologisation of education via such schemes as school-wide PBS. It is thus explicitly not the case that innovative ways are being identified to include any elusive 'psychic system' parameters of learning into monitoring technologies, as was rightly supposed impossible in Luhmann and Schorr's idea of an education technology deficit. It is rather that what it means to learn, in a form that cannot be captured in data, is being artificially reconfigured, via both learnification and datafication, into a selection of inputs and outputs that allow data to replace, entirely, a previous conception of what learning is. Learning becomes what the data are making visible, with education and effective classroom instruction being interpreted back through ends, the ability to learn, to organisationthe wide-scale induction of behaviour favourable to classroom instruction (Luhmann and Schorr 2000: 183). This inverse selection towards education in what Vanderstraeten has called an ersatz order - and that I have here determined to be essentially data-based-was the one concession that Luhmann and Schorr were ready to make with respect to the likelihood of science addressing the technology deficit in the system of education, noting the overly compact central ideas that surface with what they call 'precision engineering' (Luhmann and Schorr 2000: 232). This form of reverse engineering is precisely what has come to pass. It successfully claims to be science via the popular notion of evidence-based discovery and practice and so helps validate pedagogy as science. The latter, after all, precisely aims at abstraction; that is, at instantiating universal behavioural premises that may be changed in order to influence the education process as such, in a given direction (Luhmann and Schorr 2000: 139). If instruction is only instruction when done according to a plan, then evidence-based schemes of working that help achieve effective execution of such plans do make ideal instruments of organisation. By disregarding the conventional scientific goal of the discovery or the clarification of the education process, and instead choosing to retrofit education to scientific instruments and technologies, the system of education has become performance-driven and able to model data collection in such a way that multiplicities (individual ambivalence to instruction) and other risks associated with learning can be addressed as technology. The question that this technologising turn foregrounds is, as I noted at outset, where this leaves the possibility of being and becoming human through learning in education.

Open Access This article is distributed under the terms of the Creative Commons Attribution 4.0 International License (http://creativecommons.org/licenses/by/4.0/), which permits unrestricted use, distribution, and reproduction in any medium, provided you give appropriate credit to the original author(s) and the source, provide a link to the Creative Commons license, and indicate if changes were made.

\section{References}

Beer, D. 2015. Productive measures: Culture and measurement in the context of everyday neoliberalism. Big Data \& Society. doi:10.1177/2053951715578951.

Biesta, G. 2002. Bildung and modernity: The future of bildung in a world of difference. Studies in Philosophy and Education 21(4-5): 343-351. 
Biesta, G. 2004. Against learning. Nordisk Pedagogik 24(1): 70-82.

Biesta, G. 2009. Good education in an age of measurement: On the need to reconnect with the question of purpose in education. Educational Assessment, Evaluation and Accountability 21(1): 33-46.

Biesta, G.J.J. 2010. Why 'what works' still won't work: From evidence-based education to value-based education. Studies in Philosophy and Education 29(5): 491-503.

Biesta, G. 2015a. Improving education through research? From effectiveness, causality and technology to purpose, complexity and culture. Policy Futures in Education 14(2): 194-210.

Biesta, G. 2015b. On the two cultures of educational research, and how we might move ahead: Reconsidering the ontology, axiology and praxeology of education. European Educational Research Journal 14(1): 11-22.

Bijker, W.E. 2001. Understanding technological culture through a constructivist view of science, technology and society. In Visions of STS. Counterpoints in science, technology, and society studies, ed. S.H. Cutcliffe, and C. Mitcham, 19-34. Albany: State University of New York Press.

Bradshaw, C.P., C.W. Koth, K.B. Bevans, N. Ialongo, and P.J. Leaf. 2008. The impact of school-wide positive behavioural interventions and supports (PBIS) on the organizational health of elementary schools. School Psychology Quarterly 23(4): 462-473.

Brandt, R.C., M. Chitiyo, and M.E. May. 2014. Measures used in assessing outcomes of school-wide positive behaviour support. Journal of Research in Special Educational Needs 14(4): 229-238.

Dreeben, R. 1968. On what is learned in school. Reading: Harvard University Press.

Gage, N.A., G. Sugai, T.J. Lewis, and S. Brzozowy. 2015. Academic achievement and school-wide positive behavior supports. Journal of Disability Policy Studies 25(4): 199-209.

Grey, I., H. Lydon, and O. Healy. 2016. Positive behaviour support: What model of disability does it represent? Journal of Intellectual \& Developmental Disability 41(3): 255-266.

Hardy, I. 2015a. Data, numbers and accountability: The complexity, nature and effects of data use in schools. British Journal of Educational Studies 63(4): 467-486.

Hardy, I. 2015b. 'I'm just a numbers person': The complexity, nature and effects of the quantification of education. International Studies in Sociology of Education 25(1): 20-37.

Hardy, I., and S. Lewis. 2016. The 'doublethink' of data: Educational performativity and the field of schooling practices. British Journal of Sociology of Education 38(5): 671-685.

Hopmann, S.T. 2008. No child, no school, no state left behind: Schooling in the age of accountability. Journal of Curriculum Studies 40(4): 417-456.

Kallinikos, J., H. Ekbia, and B. Nardi. 2015. Regimes of information and the paradox of embeddedness: An introduction. The Information Society 31(2): 101-105.

Kincaid, D., G. Dunlap, L. Kern, K.L. Lane, L.M. Bambara, F. Brown, L. Fox, and T.P. Knoster. 2016. Positive behavior support: A proposal for updating and refining the definition. Journal of Positive Behavior Interventions 18(2): 69-73.

Kohn, A. 2011. Feel-bad education: And other contrarian essays on children and schooling. Boston: Beacon Press.

Latour, B. 1987. Science in action: How to follow scientists and engineers through society. Cambridge: Harvard University Press.

Latour, B. 1988. The pasteurization of France. Cambridge: Harvard University Press.

Lawn, M. 2011. Governing through data in English education. Education Inquiry 2(2): 277-288.

Lawn, M., I.J. Deary, D.J. Bartholomew, and C. Brett. 2010. Embedding the new science of research: The organised culture of Scottish educational research in the mid-twentieth century. Paedagogica Historica 46(3): 357-381.

Lewis, S., and I. Hardy. 2016. Tracking the topological: The effects of standardised data upon teachers' practice. British Journal of Educational Studies 65(2): 219-238.

Lingard, B., and S. Sellar. 2013. 'Catalyst data': Perverse systemic effects of audit and accountability in Australian schooling. Journal of Education Policy 28(5): 634-656.

Luhmann, N. 1995. Social systems. Stanford: Stanford University Press.

Luhmann, N. 1998. Observations on modernity. Stanford: Stanford University Press.

Luhmann, N. 2012. Theory of society, vol. 1. Stanford: Stanford University Press.

Luhmann, N. 2013. Theory of society, vol. 2. Stanford: Stanford University Press.

Luhmann, N., and K.-E. Schorr. 2000. Problems of reflection in the system of education. New York: Waxmann.

Luiselli, J.K., R.F. Putnam, M.W. Handler, and A.B. Feinberg. 2005. Whole-school positive behaviour support: Effects on student discipline problems and academic performance. Educational Psychology 25(2-3): 183-198. 
Madigan, K., R.W. Cross, K. Smolkowski, and L.A. Strycker. 2016. Association between schoolwide positive behavioural interventions and supports and academic achievement: A 9-year evaluation. Educational Research and Evaluation 22: 1-20.

McClelland, D.C. 1965. Toward a theory of motive acquisition. American Psychologist 20(5): 321-333.

Ozga, J. 2009. Governing education through data in England: From regulation to self-evaluation. Journal of Education Policy 24(2): 149-162.

Ozga, J. 2016. Trust in numbers? Digital education governance and the inspection process. European Educational Research Journal 15(1): 69-81.

Pirrie, A., and K. Lowden. 2004. The magic mirror: An inquiry into the purposes of education. Journal of Education Policy 19(4): 515-528.

Reinke, W.M., K.C. Herman, and M. Stormont. 2013. Classroom-level positive behavior supports in schools implementing SW-PBIS: Identifying areas for enhancement. Journal of Positive Behavior Interventions 15(1): 39-50.

Robinson, R., M. Molenda, and L. Rezabek. 2008. Facilitating learning. In Educational technology: A definition with commentary, ed. A. Januszewski, and M. Molenda, 15-48. New York: Lawrence Erlbaum Associates.

Rogers, C.R. 1969. Freedom to learn: A view of what education might become. Columbus: C. E. Merrill Pub. Co.

Sugai, G., and R.R. Horner. 2006. A promising approach for expanding and sustaining school-wide positive behavior support. School Psychology Review, Bethesda 35(2): 245-259.

Sugai, G., R.H. Horner, G. Dunlap, M. Hieneman, T.J. Lewis, C.M. Nelson, T. Scott, C. Liaupsin, W. Sailor, A.P. Turnbull, and M. Ruef. 2000. Applying positive behavior support and functional behavioral assessment in schools. Journal of Positive Behavior Interventions 2(3): 131-143.

Sørlie, M.-A., T. Ogden, and A.R. Olseth. 2015. Preventing problem behavior in school through school-wide staff empowerment: Intervention outcomes. World Journal of Educational Research 2(2): 117.

Sørlie, M.-A., T. Ogden, and A.R. Olseth. 2016. Examining teacher outcomes of the school-wide positive behavior support model in Norway: Perceived efficacy and behavior management. SAGE Open 6(2): 2158244016651914.

Tomlinson, S. 2012. The irresistible rise of the SEN industry. Oxford Review of Education 38(3): 267-286.

Van Dijck, J., and T. Poell. 2015. Higher education in a networked world: European responses to U.S. MOOCs. International Journal of Communication 9: 2674-2692.

Vanderstraeten, R. 2000a. Autopoiesis and socialization: On Luhmann's reconceptualization of communication and socialization. The British Journal of Sociology 51(3): 581-598.

Vanderstraeten, R. 2000b. Luhmann on socialization and education. Educational Theory 50(1): 1-23.

Vanderstraeten, R. 2002. The autopoiesis of educational organizations: The impact of the organizational setting on educational interaction. Systems Research and Behavioral Science 19(3): 243-253.

Vanderstraeten, R. 2004. The social differentiation of the educational system. Sociology 38(2): 255-272.

Vanderstraeten, R., and G.J.J. Biesta. 2001. How is education possible? Preliminary investigations for a theory of education. Educational Philosophy and Theory 33(1): 7-21.

Walker, H.M., R.H. Horner, G. Sugai, M. Bullis, J.R. Sprague, D. Bricker, and M.J. Kaufman. 1996. Integrated approaches to preventing antisocial behavior patterns among school-age children and youth. Journal of Emotional and Behavioral Disorders 4(4): 194-209.

Warren, J.S., H.M. Bohanon-Edmonson, A.P. Turnbull, W. Sailor, D. Wickham, P. Griggs, and S.E. Beech. 2006. School-wide positive behavior support: Addressing behavior problems that impede student learning. Educational Psychology Review 18(2): 187-198.

Woolgar, S. 1991. Beyond the citation debate: Towards a sociology of measurement technologies and their use in science policy. Science and Public Policy 18(5): 319-326. 